\title{
Induction of tetrasomy by human papillomavirus type 16 E7 protein is independent of pRb binding and disruption of
} differentiation

\author{
SA Southern', MH Lewis' and CS Herrington*,1,2 \\ 'Department of Pathology, University of Liverpool, Duncan Building, Daulby Street, Liverpool L69 3GA, UK; ${ }^{2}$ Bute Medical School, University of \\ St Andrews, St Andrews KYI6 9TS, UK
}

\begin{abstract}
We have demonstrated previously that high-risk human papillomaviruses (HPVs) induce tetrasomy in low-grade squamous intraepithelial lesions of the cervix. In this study we show that the E6 and E7 genes of high-risk HPV-I6, but not those of low-risk HPV-6, are independently able to induce tetrasomy when constitutively expressed in proliferating monolayer cultures of primary human keratinocytes. Of seven HPV-I6 E7 mutants analysed (H2P, $\Delta 6-10, \Delta 21-24, C 24 G$, S3 I G/S32G, A50S and S7II), five were severely impaired in their ability to induce tetrasomy in monolayer and raft culture. Only mutant C24G induced tetrasomy to levels comparable with wild-type E7 in monolayer and raft culture. This mutant shows strongly reduced binding to the retinoblastoma gene product $\mathrm{pRb}$. The casein kinase II phosphorylation defective mutant S3I G/S32G induced tetrasomy to levels comparable with wildtype E7 in raft culture, but not in monolayer culture, and induction of tetrasomy did not correlate with raft morphology. These results indicate that $\mathrm{pRb}$ protein binding is not required for HPV-I6 E7 associated tetrasomy and that tetrasomy is not directly related to the ability of this protein to disrupt keratinocyte differentiation.

British Journal of Cancer (2004) 90, 1949-1954. doi: I0.1038/sj.bjc.660I 827 www.bjcancer.com
\end{abstract}

Published online 20 April 2004

(C) 2004 Cancer Research UK

Keywords: human papillomavirus; keratinocyte; tetrasomy

Human Papillomaviruses (HPV) are small double-stranded DNA viruses with a strict tropism for epithelial cells and $99.7 \%$ of cervical cancers are associated with HPV infection (Walboomers et al, 1999). Particular HPV types, most notably HPV 16 and 18, predominate in this association and are thus referred to as highrisk types. In previous studies we have shown that basal cell tetrasomy occurs in low-grade squamous intraepithelial lesions of the cervix (SILs) infected with high-risk HPVs but not in those infected with low-risk HPVs (Southern et al, 1997). Tetrasomic cells contain four separate copies of each chromosome instead of two. In normal cells, replicated chromosomes remain as tightly associated sister chromatid pairs until mitosis. Sister chromatid separation is stringently regulated and only occurs after each replicated chromosome has become aligned on the mitotic spindle. In tetrasomic cells it would seem that the sister chromatids have become separated but that a subsequent step in mitosis has arrested or failed. Such failures in mitosis can lead to genetic instability and are of cardinal importance in the cancer process.

HPVs encode two small proteins, E6 and E7 that act as potent cell-cycle dysregulators and are able to drive infected cells into Sphase to allow replication of viral DNA. In a productive HPV infection the viral genome is maintained episomally and E6 and E7 are expressed at low levels under viral cis- and trans-acting control. During neoplastic progression the expression of E6 and E7

*Correspondence: Prof CS Herrington; E-mail: csh2@st-andrews.ac.uk Received 13 August 2003; accepted 3 March 2004; published online 20 April 2004 is de-repressed, usually as a result of integration of the viral DNA into the host genome. Expression of high-risk E6 and E7 proteins can immortalise primary human epithelial cells in vitro (HawleyNelson et al, 1989) and both proteins bind to numerous cellular target proteins (Kuhne and Banks, 1999; Zwerschke and JansenDurr, 2000), several of which are also targets of adenovirus and SV40 early proteins.

The best studied interaction of E7 is that with pRb (Helt and Galloway, 2003). In vitro transformation assays of mutant and chimeric E7 proteins from the archetypal high-risk type 16 and the low-risk type 6 have shown that pRb binding affinity correlates with transforming capacity (Heck et al, 1992). However, pRbbinding is not sufficient for in vitro transformation by HPV-16 E7 (Banks et al, 1990). Studies on the interaction of E7 with pRb have yielded the following model. In healthy cells, hypo-phosphorylated $\mathrm{pRb}$ associates with the transcription factor E2F and prevents its activation of transcription of many genes required for S-phase progression (e.g. DNA polymerase $\alpha$ ). As the cell progresses through $\mathrm{G} 1 \mathrm{pRb}$ is sequentially phosphorylated at various sites by cyclin-dependent kinases causing it to release E2F and permit transcription of S-phase genes. Thus pRb, in its hypo-phosphorylated state, can act as a brake on cell-cycle progression and it must be phosphorylated to allow the cell-cycle to continue to S-phase. HPV-16 E7 protein binds to hypo-phosphorylated $\mathrm{pRb}$ preventing its sequestration of E2F and potentiating its proteolytic degradation. This effectively removes one of the main nodes of cell-cycle regulation at this point and facilitates unscheduled progression into S-phase. This is potentiated by the direct binding of E7 to 
E2F1 with consequent activation of E2F1-drive transcription (Hwang et al, 2002). The role of pRb is not limited to the G1/S boundary of the cell cycle. pRb deficient fibroblasts lose the ability to sustain a G2 arrest in the presence of mitotic blocks and proceed on into G1 and then S-phase without an intervening cell division (Di Leonardo et al, 1997; Niculescu et al, 1998). Furthermore, pRb functionally interacts, specifically during G2/M, with Heclp, a protein required for proper chromosome segregation (Zheng et al, 2000). The transcription factor E2F is also involved at G2/M. DNA microarray analysis has shown that those genes transcriptionally regulated by E2F fall into two classes; those expressed at G1/S and another class expressed at G2/M (Ishida et al, 2001).

$\mathrm{pRb}$ is one member of a family of proteins that share a 'pocket' domain involved in protein/protein interactions. The three members of the pocket-protein family, pRb, p107 and p130, seem to have largely overlapping functions (Mulligan and Jacks, 1998). While $\mathrm{pRb}$ is mutated or otherwise inactivated (e.g. by HPV E7) in most human cancers, loss of function of p107 or p130 is rarely, if ever, observed. p130 predominates in quiescent or terminally differentiated cells and p107 predominates in proliferating cells. Although E7 binds to all three proteins via the pocket domain it preferentially binds p130 (Smith-McCune et al, 1999).

In a previous study we showed that tetrasomy occurs in organotypic raft culture of primary human keratinocytes (PHKs) expressing the (high-risk) HPV-18 E7 gene alone under control of the native, differentiation dependent, HPV-18 enhancer/promoter (Southern et al, 2001). Expression of HPV-18 E6 protein alone under these conditions did not cause tetrasomy. However, the E6 and E7 proteins both disrupt G2/M checkpoints in vitro (Thomas and Laimins, 1998). Hence, in the present study, we test the hypothesis that the E6 and E7 proteins of high-risk HPV can induce tetrasomy when expressed constitutively. We also test the hypothesis that the induction of tetrasomy by E7 is a result of the E7 protein's interference with $\mathrm{pRb}$ function.

\section{MATERIALS AND METHODS}

\section{Cell lines and culture}

Primary human keratinocytes from neonatal foreskin (Clonetics) were cultured in keratinocyte growth medium 2 (Clonetics). Retroviral packaging cell lines were obtained from the American Type Culture Collection (PA317 containing wild-type HPV genes; Halbert et al, 1992) or given by Dr Denise Galloway (PG13 containing mutant HPV-16 E7 genes; Demers et al, 1996) and were cultured in Dulbecco's modified Eagle's medium with $10 \%$ foetal calf serum.

\section{Transduction and selection of PHKs}

Fresh medium was applied to confluent cultures of packaging cells and allowed to accumulate virus overnight. The medium was filtered through $0.45 \mu \mathrm{m}$ cellulose acetate filters and combined with an equal volume of keratinocyte growth medium 2 containing hexadimethrine bromide (polybrene) (Sigma H9268) to a final concentration of $6 \mu \mathrm{g} \mathrm{ml}^{-1}$. In total, $4 \mathrm{ml}$ of this mixture was applied to passage 1 monolayer PHKs at approximately $10 \%$ confluency in $25 \mathrm{~cm}^{2}$ flasks. After $6 \mathrm{~h}$ the medium was removed, the cells were rinsed in PBS and fresh medium was added. Selection was begun $24 \mathrm{~h}$ later with $\mathrm{G} 418$ at $150 \mu \mathrm{g} \mathrm{ml}^{-1}$ and continued for $48 \mathrm{~h}$. Mock-infected cultures treated this way were dead by day 3 after selection.

\section{Organotypic raft culture}

A detailed protocol is described elsewhere (Wilson et al, 1992). Briefly, $10^{6}$ keratinocytes were seeded onto a collagen plug containing $5 \times 10^{5} \mathrm{~J} 2-3 \mathrm{~T} 3$ feeder cells in one well of a six-well plate and submerged in raft culture medium. When confluent the plug was transferred onto a wire mesh grid in a $10 \mathrm{~cm}$ Petri dish to raise it to the air/liquid interface above raft culture medium. The cultures were grown for 10 days then fixed in $10 \%$ neutral buffered formalin for 2 days and embedded in paraffin wax. Raft culture medium is 70\% Dulbecco's modified Eagle's medium, 25\% Ham's F12 medium, 5\% foetal calf serum supplemented with $180 \mu \mathrm{M}$ adenine, $5 \mu \mathrm{g} \mathrm{ml}^{-1}$ insulin, $400 \mathrm{ng} \mathrm{ml}^{-1}$ hydrocortisone, $5 \mu \mathrm{g} \mathrm{ml}^{-1}$ transferrin, $200 \mathrm{pM}$ 3,3',5-triiodo- ${ }_{-}$-thyronine (Sigma T6397), $100 \mathrm{pM}$ cholera toxin, $5 \mathrm{ng} \mathrm{ml}^{-1}$ epidermal growth factor, $2.5 \mu \mathrm{g} \mathrm{ml}^{-1}$ fungizone (Life Technologies), $100 \mathrm{U} \mathrm{ml}^{-1}$ penicillin $\mathrm{G}$ and $100 \mu \mathrm{g} \mathrm{ml}^{-1}$ streptomycin.

\section{PCR rescue and sequencing}

Genomic DNA was prepared using a Qiagen blood/tissue-culture small scale DNA isolation kit. LXSN vector specific flanking primers were used in standard PCR conditions to amplify an approximately $400 \mathrm{bp}$ product, which was gel-purified and subjected to automated sequencing of one strand. The results were unambiguous in each case.

\section{Interphase cytogenetics}

Monolayer cells were trypsinized, allowed to attach to glass slides overnight in a droplet of medium in a $\mathrm{CO}_{2}$ incubator at $37^{\circ} \mathrm{C}$ and fixed by immersion in 10\% neutral buffered formalin for 2 days. Slides were previously treated with aminopropyltriethoxysilane (Sigma A3648). $6 \mu \mathrm{m}$ sections of paraffin embedded raft cultures were taken onto treated slides, heated overnight at $60^{\circ} \mathrm{C}$, dewaxed in xylene and rehydrated through an ethanol series. The method of hybridisation is described in detail elsewhere (Southern and Herrington, 1996). Briefly, slides were pretreated with sodium thiocyanate, pepsin/ $\mathrm{HCl}$ and hybridized with biotin or digoxigenin labelled alpha-satellite probes specific to either chromosome 1, 3 or 17 . The chromosome 1 probe was kindly provided by $\mathrm{Dr} \mathrm{AH}$ Hopman (University of Limburg, Maastricht, the Netherlands) and the chromosome 3 and 17 probes were purchased from Appligene/ Oncor. Signal was detected with peroxidase conjugated antibodies, diaminobenzidine and hydrogen peroxide.

\section{Scoring tetrasomy}

Nuclei were classified at $\times 630$ magnification into five classes depending on the number of spots present: $1,2,3,4$ and $5+$ spots. In monolayer culture the percentage tetrasomy is the number of 4spot nuclei divided by the total $\times 100$. In raft culture sections many nuclei are truncated. We have shown previously that sectioned material from a purely tetrasomic population produces a signal distribution containing approximately equal numbers of nuclei containing 3 and 4 spots (Southern and Herrington, 1996). Therefore, the 3- and 4-spot classes were combined and classed as tetrasomic. The $P$-values derived using $\chi^{2}$ comparisons were multiplied by the number of comparisons, 6 in Figure 1 and 8 in Figure 2 (a Bonferroni correction), to avoid type I errors (Altman, 1991). $95 \%$ confidence interval is $-1.96 \mathrm{SE}$ to $+1.96 \mathrm{SE}$.

\section{RESULTS}

The E6 and E7 genes of HPV type 16, but not those of type 6 , are independently able to induce tetrasomy in primary human keratinocyte monolayer culture

We investigated constitutive expression of both the E6 and E7 genes of the archetypal high-risk type 16, and also of the low-risk type $6 \mathrm{HPV}$, by obtaining PA317 retrovirus packaging cell lines generated in the laboratory of Dr Denise Galloway (Halbert et al, 1992), which contain the following genes inserted into the LXSN retroviral vector: HPV16 E6 \& E7, HPV6 E6 \& E7 and LXSN vector alone (ATCC, Manassas, VA, USA). In these constructs the 


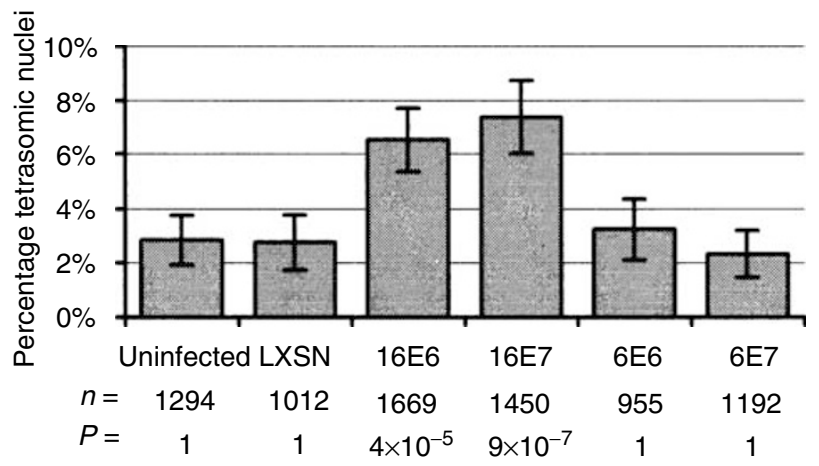

Figure I Percentage tetrasomy induced in monolayer culture of PHKs expressing of HPV-16 and HPV-6 E6 and E7 proteins. Indicated beneath each bar is the number of nuclei counted $(n)$ and the Bonferroni corrected $P$-value $(P)$ based on a $\chi^{2}$ test using two-way contingency tables compared to uninfected. The error bars show the $95 \%$ confidence interval assuming a normal distribution.

inserted genes are transcribed from the constitutive promoter in the moloney murine leukaemia retroviral LTR. Primary human keratinocytes growing as submerged monolayers were transduced with retrovirus at passage 1, selected with G418 for 2 days and then allowed to expand. The cultures were fixed and analysed at passage 3 ( 7 days after transduction for the HPV-16 constructs, 10-14 days for the others). The cells were analysed by interphase cytogenetics using biotinylated DNA probes specific for chromosomes 1, 3 and 17. We have previously shown that HPV-induced tetrasomy involves at least chromosomes $1,3,4,6,10,11,17,18$ and $\mathrm{X}$ (Giannoudis et al, 2000). The results are shown in Figure 1. Significantly increased levels of tetrasomy occured in cultures transduced with retroviruses expressing HPV16 E6 and E7 genes. Those cultures transduced with retroviruses expressing HPV6 E6 or E7, as well as cultures transduced with LXSN vector, showed no significant increase in levels of tetrasomy above uninfected PHKs. Thus, the ability of these HPV proteins to induce tetrasomy correlates with their ability to transform cells in vitro.

\section{High affinity $\mathrm{pRb}$ binding is not required for induction of tetrasomy by HPV16 E7}

In order to map the domains of E7 required for its induction of tetrasomy, we investigated seven HPV16 E7 mutants: H2P, $\Delta 6-10$, $\Delta 21-24$, C24G, S31G/S32G, A50S and S71I. These mutants, the gift of Dr Denise Galloway (Demers et al, 1996), were in the form of LXSN constructs in PG13 retrovirus packaging cell lines. HPV-16 E7 protein has been notionally divided into domains based on sequence homology to widely separated regions of the much larger adenovirus E1a protein. Mutations $\mathrm{H} 2 \mathrm{P}$ and $\Delta 6-10$ are located in conserved region 1 (CR1), mutations $\Delta 21-24, \mathrm{C} 24 \mathrm{G}$ and S31G/ S32G are located in CR2 and mutations A50S and S71I are located close to the C-terminal metal-binding domain (Figure 2A). PHKs were transduced at passage 1 , selected for 2 days, expanded for 3 4 days then split and grown in parallel as submerged monolayer and organotypic raft cultures. Expression of the mutant proteins under these conditions has been demonstrated previously (Demers et al, 1996). Monolayer cultures were fixed at passage 3. Raft cultures were grown for 10 days before fixation. After fixation the presence of the correct mutant gene was confirmed in each case by PCR rescue and sequencing. Tetrasomy was scored by interphase cytogenetics using biotinylated DNA probes specific for chromosomes 1, 3 and 17. Only the C24G mutant E7 protein was able to induce levels of tetrasomy similar to wild-type HPV16 E7 in monolayer culture (Figure 2B). The other mutants all showed strongly reduced levels of tetrasomy with least loss of effect being shown by the C-terminal mutants A50S and S71I. In raft culture
A
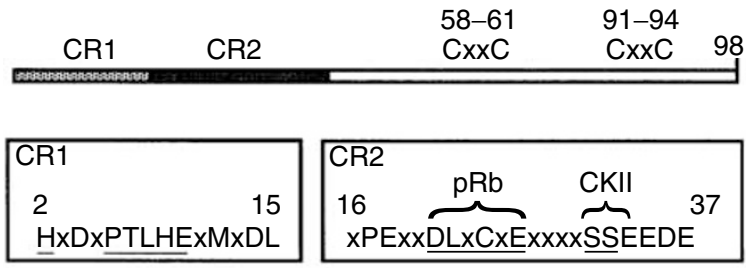

B

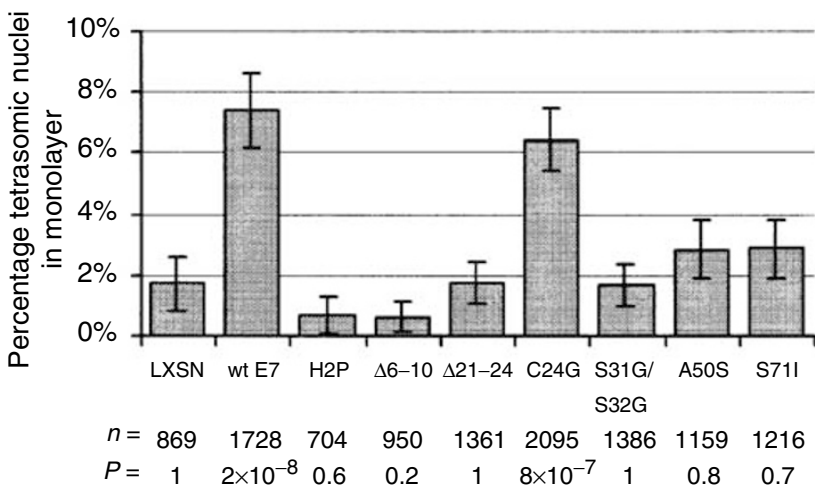

C

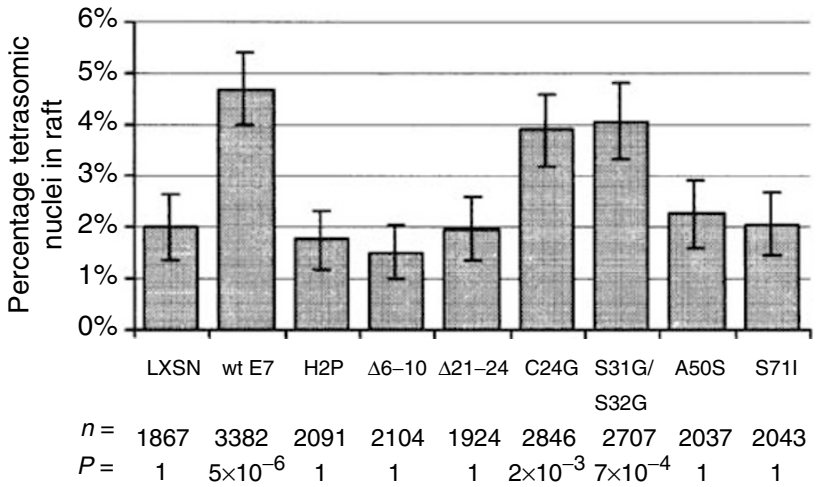

Figure 2 Induction of tetrasomy by HPV-16 E7 mutant proteins. (A) Schematic diagram of HPV-16 E7 protein showing sequence homology with adenovirus Ela in the conserved regions CRI and CR2. Positions of mutations in CRI and CR2 are underlined. The locations of pRb binding and CKII phosphorylation sites are indicated. (B) Percentage tetrasomy induced by mutant HPV-I6 E7 proteins in monolayer culture of PHKs. (C) Percentage tetrasomy induced by mutant HPV-I6 E7 proteins in organotypic raft culture of $\mathrm{PHKs}$. Indicated beneath each bar is the number of nuclei counted $(n)$ and the Bonferroni corrected $P$-value $(P)$ based on a $\chi^{2}$ test using two-way contigency tables compared to LXSN. The error bars show the $95 \%$ confidence interval assuming a normal distribution.

the same pattern emerged with the exception that the S31G/S32G protein gave a similar level of tetrasomy to wild type and C24G (Figure 2C). The tetrasomy was predominantly suprabasal (data not shown).

The ability of HPV16 E7 to induce tetrasomy is separable from its ability to disrupt keratinocyte differentiation in organotypic raft culture

Haematoxylin and eosin stained sections show three different morphological groups in the organotypic raft cultures (Figure 3). 


\section{A}
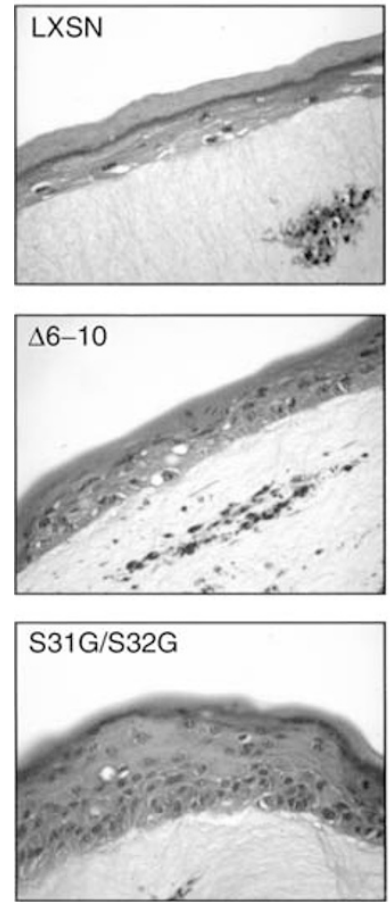

B

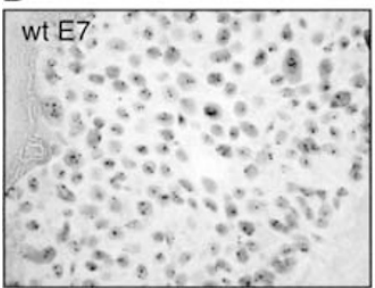

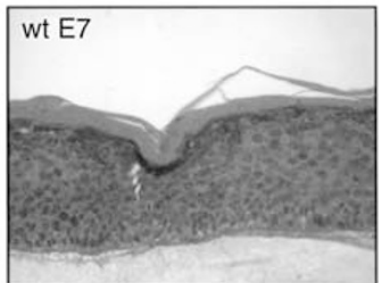
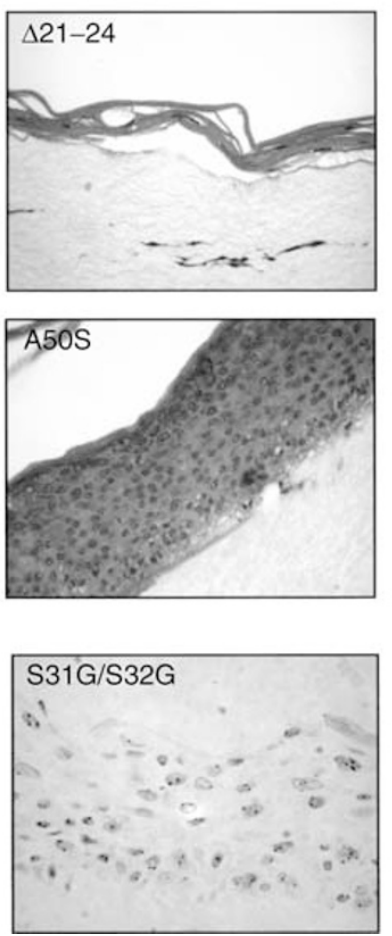
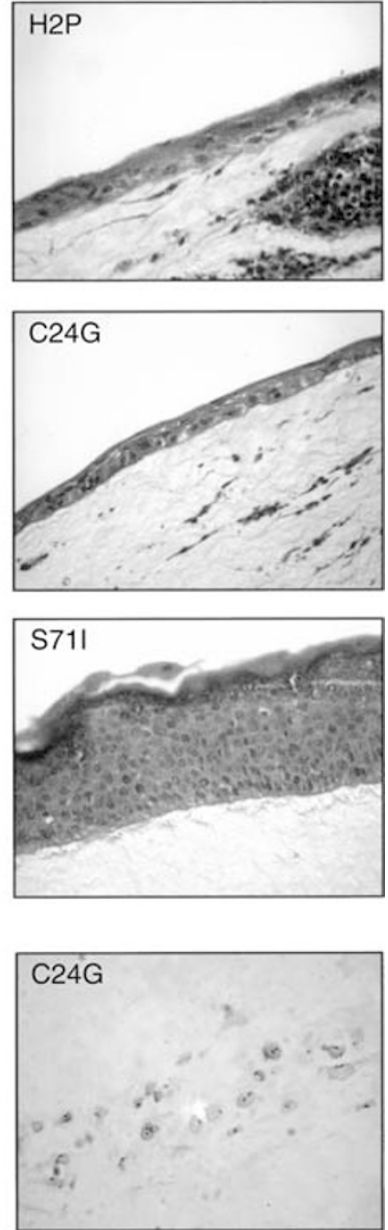

Figure 3 (A) Haematoxylin and eosin stained sections of organotypic raft cultures of PHKs transduced with retrovirus expressing HPV-16 E7 mutant proteins. Magnification $\times 400$. (B) Interphase cytogenetic staining of a raft culture section from each of the three morphological categories with a chromosome 17 specific probe. Nuclei counterstained with haematoxylin. Magnification $\times 630$.

In the first group, represented by wild-type HPV-16 E7 and the mutant proteins A50S and S71I, a thick epithelium is formed containing uniformly undifferentiated cells throughout. The second group, represented by the mutant proteins $\mathrm{H} 2 \mathrm{P}, \Delta 6-10$, $\Delta 21-24$ and $\mathrm{C} 24 \mathrm{G}$, as well as the LXSN vector, forms a very thin epithelium containing differentiated cells. The third group, represented only by mutant protein $\mathrm{S} 31 \mathrm{G} / \mathrm{S} 32 \mathrm{G}$, shows a thick epithelium with distinct layers of basal (undifferentiated) and spinous (differentiated) cells. Those E7 proteins inducing tetrasomy in raft culture do not fall into any particular morphological class. Induction of tetrasomy occurs in rafts from each class, namely HPV-16 E7 wild type, C24G and S31G/S32G. Thus, the ability of HPV-16 E7 mutant proteins to induce tetrasomy does not correlate with any particular effect on keratinocyte differentiation in raft culture.

\section{DISCUSSION}

In earlier studies we have shown that tetrasomy occurs in a proportion of low-grade SILs infected with high-risk HPV types but does not occur in SILs infected with low-risk HPV types (Giannoudis et al, 2000). We also identified tetrasomy in suprabasal keratinocytes in raft cultures expressing HPV 18 E7, but not in rafts expressing E6, under transcriptional control of the native HPV-18 enhancer/promoter (Southern et al, 2001).
However, the HPV-18 enhancer/promoter is strongly repressed in basal cells and becomes derepressed when the cells migrate up the epithelium and begin to differentiate. Hence, the ability of these genes to induce tetrasomy in proliferating cells cannot be assessed. Moreover, both E6 and E7 have been shown independently to disrupt G2/M cell-cycle checkpoints in vitro (Thomas and Laimins, 1998). Therefore, in this study, we tested the hypothesis that constitutive expression of both of these genes can induce tetrasomy in proliferating cells. In monolayer culture, which most closely approximates the basal/parabasal proliferating layer of an epithelium, both E6 and E7 of HPV-16 were able to induce tetrasomy. In contrast, the E6 and E7 genes of the low-risk HPV type 6 were not able to induce tetrasomy. These findings are consistent with the known biochemical properties of these proteins.

To investigate further the induction of tetrasomy by HPV-16 E7 protein, we analysed monolayer and raft cultures of PHKs transduced with retroviruses expressing mutant E7 proteins. These seven are distributed throughout the protein and are well characterised with respect to pRb-binding and transformation (Demers et al, 1996). All but one of the mutants showed a significant reduction in tetrasomy compared to wild-type E7 in monolayer culture. This suggests that no single domain of the E7 protein is responsible for the effect and that induction of tetrasomy is an indirect downstream effect of two or more E7 functions residing in different parts of the protein. 
The one mutant protein that did not cause a reduction in tetrasomy was $\mathrm{C} 24 \mathrm{G}$. This substitution to glycine of the central cysteine of the $\mathrm{xLxCxE}$ motif has been reported to abrogate binding to $\mathrm{pRb}$ (Davies et al, 1993; Demers et al, 1996) and p130 (Smith-McCune et al, 1999), and to either reduce (Davies et al, 1993) or abrogate (Demers et al, 1996) binding to p107. This suggests that $\mathrm{pRb}$-binding is not required for induction of tetrasomy. The related mutant $\Delta 21-24$, a deletion of $\mathrm{xLxC}$ from the $\mathrm{xLxCxE}$ motif, is also unable to bind pRb or p107 (Davies et al, 1993; Phelps et al, 1992) but shows no induction of tetrasomy. What is the functional difference between the C24G and the $\Delta 21-$ 24 mutations? Both mutant proteins are unable to disrupt keratinocyte differentiation (Demers et $a l, 1996$ and see Figure $3 \mathrm{~A}$ ), transactivate the adenovirus E2 promoter (Edmonds and Vousden, 1989; Phelps et al, 1992) or transform cells in vitro (Edmonds and Vousden, 1989; Phelps et al, 1992). However, the C24G mutant protein is able to stimulate proliferation in immortalized rodent fibroblasts (Caldeira et al, 2000). Furthermore, recent quantitative binding studies have shown that the C24G mutant retains $30 \%$ of the pRb-binding affinity of the wildtype E7 protein (apparent $\mathrm{K}_{\mathrm{D}} \mathrm{s}$ of 14 and $4.5 \mathrm{~nm}$ respectively) (Dong et al, 2001). Nevertheless, this mutant, which exhibits $70 \%$ reduction in $\mathrm{pRb}$ binding affinity, was able to induce a similar of level of tetrasomy to wild-type protein. Thus, it can still be inferred that induction of tetrasomy by E7 is not directly related to $\mathrm{pRb}$ binding. However, if $\mathrm{C} 24 \mathrm{G}$ retains or accentuates some difference in binding preference between the pocket proteins then the direct involvement of p107 or p130 cannot be excluded. Alternatively, the mechanism of induction of tetrasomy may be independent of pocket-protein binding altogether. The $\Delta 21-24$ deletion mutant is completely unable to bind to $\mathrm{pRb}$ and does not induce tetrasomy. The difference between the findings for this mutant and those for C24G may in part be related to a change (possibly conformational) that impinges on some other E7 function additional to pocketprotein binding that is not affected by C24G. The other mutants analysed are able to bind to pRb but, with the exception of S31G/ S32G in raft culture, are unable to induce tetrasomy. Thus, induction of tetrasomy does not segregate with $\mathrm{pRb}$ binding.

In organotypic raft culture $\mathrm{C} 24 \mathrm{G}$ was joined by $\mathrm{S} 31 \mathrm{G} / \mathrm{S} 32 \mathrm{G}$ in possessing the ability to induce tetrasomy, which was predominantly suprabasal, to levels comparable with wild-type protein. The two serines at positions 31 and 32 form part of the recognition site for, and are phosphorylated by, casein kinase II. It is not clear why the S31G/S32G mutant cannot induce tetrasomy in monolayer but is capable of doing so in raft culture, but this differential ability is compatible with our previous hypothesis that the mechanisms of induction of basal and suprabasal tetrasomy are different (Southern et al, 2001). In monolayer culture the cells are undifferentiated and cycling and most closely resemble the basal/parabasal layer of an epithelium. Expression of E7 protein in these cells may disrupt cell-cycle checkpoints, leading to tetrasomy, and our data suggest that this property requires phosphorylation of the S31/S32 site. In raft culture the keratinocytes form a squamous epithelium and the E7 protein induces unscheduled DNA synthesis in a proportion of postmitotic, differentiated keratinocytes (Cheng et al, 1995). Our data suggest that phosphorylation at the S31/S32 site is not required for this function. Only the S31G/S32G mutant gave a raft morphology indicating both proliferation (a thickened raft) and differentiation. Therefore, mutation of the CKII phosphorylation site reduces the ability of the E7 protein to disrupt keratinocyte differentiation but has no effect on induction of tetrasomy. Further analysis of other mutations in the CR2 region of HPV-16 E7 may clarify the mechanism.

The other rafts were either proliferative but relatively undifferentiated (wild-type, A50S, S71I) or nonproliferative (vector, H2P, $\Delta 6-10, \Delta 21-24, C 24 G)$, in agreement with the findings of Demers et al (1996). The induction of tetrasomy by C24G, S31G/S32G and wild-type E7 demonstrates that this property is not related to the ability of the E7 protein to disrupt keratinocyte differentiation. The proportion of keratinocytes with detectable tetrasomy was relatively low but this is compatible both with our previous study (Southern et al, 2001) and with observations reported by others (Chien et al, 2002). The latter study provided evidence that postmitotic, differentiated keratinocytes expressing high-risk HPV E7 protein have alternative fates, with only a minority undergoing endoreduplication, consistent with our data.

The absence of tetrasomy in rafts expressing C-terminal mutants A50S and S71I is consistent with the observation that, despite their ability to bind to $\mathrm{pRb}, \mathrm{C}$-terminal mutations inhibit the ability of E7 to induce $S$ phase and endoreduplication in differentiated keratinocytes and is compatible with the requirement for inactivation of both $\mathrm{pRb}$ and $\mathrm{p} 21$ by HPV 16 E7 in order to bypass cell-cycle arrest (Helt et al, 2002). The requirement for factors additional to abrogation of the p16INK4A/pRb checkpoint for induction of centrosome abnormalities during keratinocyte immortalisation supports the involvement of additional E7 functions (Piboonniyom et al, 2003). Thus, centrosome abnormalities were demonstrable in keratinocytes immortalised by a combination of HPV 16 E7 and hTERT but not in those immortalised by cdk4/hTERT or by hTERT alone, the latter having lost expression of p16INK4A.

In summary, both the E6 and E7 proteins of HPV 16 can induce tetrasomy in proliferating keratinocytes. Mutational analysis of the E7 protein shows that the ability of E7 to induce tetrasomy is separable from both $\mathrm{pRb}$ binding and disruption of keratinocyte differentiation, indicating that this phenomenon is not directly related to either of these properties and is likely to require multiple functions of the E7 protein.

\section{ACKNOWLEDGEMENTS}

This work was supported by the University of Liverpool and by North West Cancer Research Fund grant CR493.

\section{REFERENCES}

Altman DG (1991) Practical Statistics for Medical Research. London: Chapman \& Hall

Banks L, Edmonds C, Vousden KH (1990) Ability of the HPV16 E7 protein to bind $\mathrm{RB}$ and induce DNA synthesis is not sufficient for efficient transforming activity in NIH3T3 cells. Oncogene 5: 1383-1389

Caldeira S, de Villiers EM, Tommasino M (2000) Human papillomavirus E7 proteins stimulate proliferation independently of their ability to associate with retinoblastoma protein. Oncogene 19: 821-826

Cheng S, Schmidt-Grimminger DC, Murant T, Broker TR, Chow LT (1995) Differentiation-dependent up-regulation of the human papillomavirus E7 gene reactivates cellular DNA replication in suprabasal differentiated keratinocytes. Genes Dev 9: 2335-2349
Chien W-M, Noya F, Benedict-Hamilton H, Broker YTR, Chow LT (2002) Alternative fates of keratinocytes transduced by human papillomavirus type 18 E7 during squamous differentiation. J Virol 76: 2964-2972

Davies R, Hicks R, Crook T, Morris J, Vousden K (1993) Human papillomavirus type 16 E7 associates with a histone $\mathrm{H1}$ kinase and with p107 through sequences necessary for transformation. J Virol 67: 2521-2528

Demers WG, Espling E, Harry JB, Etscheid BG, Galloway DA (1996) Abrogation of growth arrest signals by human papillomavirus type 16 E7 is mediated by sequences required for transformation. $J$ Virol 70: $6862-6869$

Di Leonardo A, Khan SH, Linke SP, Greco V, Seidita G, Wahl GM (1997) DNA rereplication in the presence of mitotic spindle inhibitors in human 
and mouse fibroblasts lacking either p53 or pRb function. Cancer Res 57: 1013 - 1019

Dong WL, Caldeira S, Sehr P, Pawlita M, Tommasino M (2001) Determination of the binding affinity of different human papillomavirus E7 proteins for the tumour suppressor $\mathrm{pRb}$ by a plate-binding assay. J Virol Methods 98: 91 -98

Edmonds C, Vousden KH (1989) A point mutational analysis of human papillomavirus type 16 E7 protein. J Virol 63: $2650-2656$

Giannoudis A, Evans MF, Southern SA, Herrington CS (2000) Basal keratinocyte tetrasomy in low-grade squamous intra-epithelial lesions of the cervix is restricted to high and intermediate risk HPV infection but is not type-specific. Br I Cancer 82: 424-428

Halbert CL, Demers GW, Galloway DA (1992) The E6 and E7 genes of human papillomavirus type 6 have weak immortalizing activity in human epithelial cells. J Virol 66: $2125-2134$

Hawley-Nelson P, Vousden KH, Hubbert NL, Lowy DR, Schiller JT (1989) HPV 16 E6 and E7 protein cooperate to immortalise human foreskin keratinocytes. EMBO J 8: 3905-3910

Heck DV, Yee CL, Howley PM, Munger K (1992) Efficiency of binding the retinoblastoma protein correlates with the transforming capacity of the E7 oncoproteins of the human papillomaviruses. Proc Natl Acad Sci (USA) 89: $4442-4446$

Helt A-M, Funk JO, Galloway DA (2002) Inactivation of both the retinoblastoma tumor suppressor and $\mathrm{p} 21$ by the human papillomavirus type 16 E7 oncoprotein is necessary to inhibit cell cycle arrest in human epithelial cells. J Virol 76: $10559-10568$

Helt A-M, Galloway DA (2003) Mechanisms by which DNA tumor virus oncoproteins target the $\mathrm{Rb}$ family of pocket proteins. Carcinogenesis 24 : $159-169$

Hwang SG, Lee D, Kim J, Seo T, Choe J (2002) Human papillomavirus type 16 E7 binds to E2F1 and activates E2F1-driven transcription in a retinoblastoma protein-dependent manner. J Biol Chem 277: 2923 - 2930

Ishida S, Huang E, Zuzan H, Spang R, Leone G, West M, Nevins JR (2001) Role for E2F in control of both DNA replication and mitotic functions as revealed from DNA microarray analysis. Mol Cell Biol 21: 4684-4699

Kuhne C, Banks L (1999) Cellular targets of the papillomavirus E6 proteins. Papillomavirus Rep 10: 139-145

Mulligan G, Jacks T (1998) The retinoblastoma gene family: cousins with overlapping interests. Trends Genet 14: 223-229
Niculescu AB, Chen X, Smeets M, Hengst L, Prives C, Reed SI (1998) Effects of $\mathrm{p} 21$ (Cip1/Waf1) at both the G1/S and the G2/M cell cycle transitions: $\mathrm{pRb}$ is a critical determinant in blocking DNA replication and in preventing endoreduplication. Mol Cell Biol 18: 629-643

Phelps WC, Munger K, Yee CL, Barnes JA, Howley PM (1992) Structure function analysis of the human papillomavirus type 16 E7 oncoprotein. J Virol 66: $2418-2427$

Piboonniyom S, Duensing S, Swilling N, Hasskari J, Hinds PW, Munger K (2003) Abrogation of the retinoblastoma tumor suppressor checkpoint during keratinocyte immortalisation is not sufficient for induction of centrosome-mediated genomic instability. Cancer Res 63: 476-483

Smith-McCune K, Kalman D, Robbins C, Shivakumar S, Yuschenkoff L, Bishop JM (1999) Intranuclear localization of human papillomavirus 16 E7 during transformation and preferential binding of E7 to the Rb family member p130. Proc Natl Acad Sci USA 96: 6999-7004

Southern SA, Evans MF, Herrington CS (1997) Basal cell tetrasomy in lowgrade cervical squamous intraepithelial lesions infected with high-risk human papillomaviruses. Cancer Res 57: 4210-4213

Southern SA, Herrington CS (1996) Assessment of intra-tumoral karyotypic heterogeneity by interphase cytogenetics in paraffin wax sections. J Clin Pathol: Mol Pathol 49: M283 - M289

Southern SA, Noya F, Meyers C, Broker TR, Chow LT, Herrington CS (2001) Tetrasomy is induced by human papillomavirus type 18 E7 gene expression in keratinocyte raft culture. Cancer Res 61: 4858-4863

Thomas JT, Laimins LA (1998) Human papillomavirus oncoproteins E6 and E7 independently abrogate the mitotic spindle checkpoint. J Virol 72: $1131-1137$

Walboomers JM, Jacobs MV, Manos MM, Bosch FX, Kummer JA, Shah KV, Snijders PJ, Peto J, Meijer CJ, Munoz N (1999) Human papillomavirus is a necessary cause of invasive cervical cancer worldwide. I Pathol 189: 12 - 19

Wilson JL, Dollard SC, Chow LT, Broker TR (1992) Epithelial-specific gene expression during differentiation of stratified primary human keratinocyte cultures. Cell Growth Differ 3: $471-483$

Zheng L, Chen Y, Riley DJ, Chen PL, Lee WH (2000) Retinoblastoma protein enhances the fidelity of chromosome segregation mediated by hsHeclp. Mol Cell Biol 20: 3529-3537

Zwerschke W, Jansen-Durr P (2000) Cell transformation by the E7 oncoprotein of human papillomavirus type 16: interactions with nuclear and cytoplasmic target proteins. Adv Cancer Res 78: 1-29 